\title{
Differential Scanning Calorimetry and Infrared Spectroscopy Combined with Chemometric Analysis to the Determination of Coffee Adulteration by Corn
}

\author{
Ariadne M. Brondi,* Claudia Torres, Jerusa S. Garcia and Marcello G. Trevisan \\ Instituto de Química, Universidade Federal de Alfenas (UNIFAL-MG), 37130-000 Alfenas-MG, Brazil
}

\begin{abstract}
Roasted and ground coffee is targeted by fraudulent addiction of products. In this way the determination of contaminants in coffee has economic and nutritional importance. In this study, the coffee adulteration by corn were detected using DSC (differential scanning calorimetry) and FTIR (Fourier transform infrared spectroscopy) coupled to PCA (principal component analysis), and PLS (partial least squares) models. Three different levels of roasted and ground Coffea arabica L. were used to prepare mixtures with roasted and ground corn. The level of adulteration used was between 0.5 to $40 \%(\mathrm{~m} / \mathrm{m})$. It was observed that both DSC and FTIR coupled with PCA are able to discriminate adulterated from unadulterated samples of coffee by corn at levels below $1 \%$. PLS models were built with DSC and FTIR data reaching good correlation between the values of estimated and reference concentrations, with RMSECV (root mean square error of cross-validation) lower than $3.5 \%$ for DSC data and $2.7 \%$ for FTIR data.
\end{abstract}

Keywords: coffee, adulteration, DSC, ATR-FTIR, chemometric analysis

\section{Introduction}

The coffee drink is consumed throughout the world for being a symbol of hospitality, has stimulant properties and pleasant taste, which makes it an international commodity. ${ }^{1}$ According to ICO (International Coffee Organization), global coffee consumption were about 150 million of bags or 9 million tons in 2014, and the estimate is an annual increase of $2.3 \% .^{2}$ Brazil is the leading exporter of coffee in the world. In 2015, Brazil exported 36.32 million bags of $60 \mathrm{~kg}$, an increase of $2.7 \%$ relative to 2014 , representing a revenue of US\$ 6.15 billion only in exports, according to CECAFÉ (Council of coffee exporters from Brazil). ${ }^{3}$ The estimate world production in 2016 is 155.7 million of bags. ${ }^{4}$

Due to the economic importance of coffee, the roasted and ground coffee turns target of adulterants by mixing lower value products that have similar physical characteristics, like: bark and branches of coffee, corn, rice, barley, rye and caramelized sugar. However, the adulterations not only generates higher profits for traders, but also loss in quality (smell and taste) and nutritional value of the product, being dangerous in cases of foodborne illness. ${ }^{5-7}$ To this study, the adulteration by corn was chosen because corn is common in south region of Minas Gerais State and have low cost value in relation to coffee.

*e-mail: ariadnebrondi@yahoo.com.br
The Normative Instruction No. 16, May 24, 2010 of MAPA (Brazilian Ministry of Agriculture and Supply) has the aim of assurance in the quality of roasted and ground coffee, and preconize that the maximum level allowed of impurities (rusks, sediment, waste from the coffee, seeds from another species, etc.) is $1 \%(\mathrm{~m} / \mathrm{m}) .^{5}$

Some analytical methods used in the analysis of adulterations in coffee are gas $(\mathrm{GC})^{8,9}$ and liquid chromatography (LC), ${ }^{1,10}$ electrophoresis, ${ }^{11}$ microscopy ${ }^{12}$ and infrared spectroscopy., ${ }^{7,13-16}$ These methods requires some kind of sample manipulation before the analysis, which is a critical step.

The thermal analysis, like DSC (differential scanning calorimetry), presents potential to detect adulterations because it is a technique that allows determining the purity and can provide quantitative information without the need of an elaborated sample preparation. ${ }^{17}$ DSC technique was successfully used to detect and/or quantify adulterants in extra virgin olive oil, ${ }^{18,19}$ canola oil, ${ }^{20,21}$ virgin coconut oil, ${ }^{22}$ sunflower oil,,${ }^{23}$ honey, ${ }^{24,25}$ butter, ${ }^{26}$ animal hair fibres ${ }^{27}$ and animal fat. ${ }^{17}$ For example, the study conducted by Jafari et $a l .{ }^{28}$ comparing GC, NMR (nuclear magnetic resonance) and DSC methods to detect adulteration in Iranian olive oils, showed that the traditional analysis by GC can be complemented, or substituted by modern techniques, like NMR or DSC.

The infrared spectroscopy is a very common 
technique used to detect and quantify adulterants in many different kinds of products, like foods, ${ }^{29-37}$ pharmaceutical drugs, ${ }^{38,39}$ and drugs of abuse. ${ }^{40}$ There are a great number of works in literature about analysis of coffee using infrared spectroscopy, in special DRIFTS (diffuse reflectance infrared Fourier transform spectroscopy). ${ }^{7,13-16,41}$ According to these authors, in general DRIFTS provides spectra with higher intensity of absorption than ATR-FTIR (attenuated total reflectance Fourier transform infrared spectroscopy), and because of it DRIFTS can present better results, allowing complete discrimination between adulterated and non-adulterated coffee samples. ${ }^{7,15,41}$ However, ATR-FTIR has the region between $1500-400 \mathrm{~cm}^{-1}$, which is referred to as the fingerprint region. Absorption bands in this region are generally due to molecules and bonds vibrations, which are specific to each molecular composition and structure, allowing high selectivity data and potential for detect and quantify adulterations in coffee samples. ${ }^{42}$

The aim of this study was to evaluate the methodologies using DSC and ATR-FTIR coupled with chemometric analysis to detect and quantify the adulterations of roasted and ground Coffea arabica $L$. by corn. To discriminate the adulterated samples of coffee from non-adulterated ones were built PCA (principal component analysis) models, and to quantify the level of adulterations were built PLS (partial least squares) models.

\section{Experimental}

\section{Materials}

The green coffee beans used to develop this work are Coffea arabica $L$. and it were obtained from Prof Dr Rosemary G. F. A. Pereira (Universidade Federal de Lavras, UFLA). The coffee beans were roasted in three different levels: light (at $235^{\circ} \mathrm{C}$ for 15 minutes), medium (at $240{ }^{\circ} \mathrm{C}$ for 20 minutes) and dark roasts (at $250{ }^{\circ} \mathrm{C}$ for 25 minutes). The corn sample employed to coffee adulteration was purchased from local market and roasted at $240{ }^{\circ} \mathrm{C}$ in muffle during 10 minutes (until acquire the same color of roasted coffee). The process of roasting corn did not occur in the roaster to prevent contamination of it. After roasting, coffee and corn were ground using a traditional coffee grinder and sieved (35-65 mesh).

Eleven binary mixtures containing coffee (in different levels of roast) and corn were prepared in a range of 0.5 to $40 \%(\mathrm{~m} / \mathrm{m})$ proportion related to corn (Table 1) using an analytical balance (Sartorius CP2P). The total weight of each mixture was $100 \mathrm{mg}$. Each sample was mixed by vortex for 5 minutes until homogenised.
Table 1. Composition of samples

\begin{tabular}{lccc}
\hline DSC samples $^{\mathrm{a}}$ & ATR-FTIR samples $^{\mathrm{b}}$ & $\begin{array}{c}\text { Coffee / } \\
(\% \mathrm{~m} / \mathrm{m})\end{array}$ & $\begin{array}{c}\text { Corn / } \\
(\% \mathrm{~m} / \mathrm{m})\end{array}$ \\
\hline 10,21 and 32 & $10-12,43-45$ and 76-78 & 60 & 40 \\
11,22 and 33 & $13-15,46-48$ and 79-81 & 65 & 35 \\
12,23 and 34 & $16-18,49-51$ and 82-84 & 70 & 30 \\
13,24 and 35 & $19-21,52-54$ and $85-87$ & 75 & 25 \\
14,25 and 36 & 22-24, 55-57 and 88-90 & 80 & 20 \\
15,26 and 37 & 25-27, 58-60 and 91-93 & 85 & 15 \\
16,27 and 38 & $28-30,61-62$ and 94-96 & 90 & 10 \\
17,28 and 39 & $31-33,64-66$ and 97-99 & 95 & 5 \\
18,29 and 40 & $34-36,67-69$ and 100-102 & 97 & 3 \\
19,30 and 41 & 37-39, 70-72 and 103-105 & 99 & 1 \\
20,31 and 42 & $40-42,73-75$ and 106-108 & 99.5 & 0.5 \\
\hline
\end{tabular}

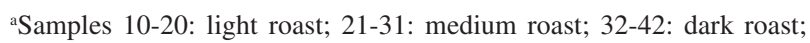
${ }^{\mathrm{b}}$ samples 10-42: light roast; 43-75: medium roast; 76-108: dark roast.

\section{Methods}

\section{Differential scanning calorimetry (DSC)}

DSC experiments were conducted using a differential scanning calorimeter; model DSC-7020 EXSTAR (SII NanoTechnology Inc.). Samples (approximately $3.0 \mathrm{mg}$ ) were placed in hermetically sealed aluminum pans and heated from an initial temperature of $50{ }^{\circ} \mathrm{C}$ to a final temperature of $600{ }^{\circ} \mathrm{C}$ in a heating rate of $10^{\circ} \mathrm{C} \mathrm{min}^{-1}$, under a dynamic nitrogen atmosphere $\left(100 \mathrm{~mL} \mathrm{~min}^{-1}\right)$. The DSC cell was previously calibrated with indium (purity greater than $99.99 \%$, Tonset $=156.6 \pm 0.3{ }^{\circ} \mathrm{C}$, and heat of fusion of $28.6 \pm 0.5 \mathrm{~J} \mathrm{~g}^{-1}$ ). After analysis, the DSC curves were converted in a matrix of temperature by heat-flow, exported to Matlab software and chemometrics analysis were conduced.

\section{Thermogravimetric analysis (TG/DTG)}

TG/DTG (thermogravimetry/differential thermogravimetry) curves were recorded on a thermogravimetric analyzer model TG/DTA7300 EXSTAR (SII NanoTechnology Inc.) employing the following parameters: temperature range of $25-600{ }^{\circ} \mathrm{C}$; dynamic nitrogen atmosphere $\left(50 \mathrm{~mL} \mathrm{~min}{ }^{-1}\right)$; heating rate of $10{ }^{\circ} \mathrm{C} \mathrm{min}^{-1}$; $\mathrm{Al}_{2} \mathrm{O}_{3}$ crucibles; and approximately $10 \mathrm{mg}$ of sample.

Attenuated total reflectance - Fourier transform infrared spectroscopy (ATR-FTIR)

Infrared spectra were recorded at room temperature $\left(25^{\circ} \mathrm{C}\right)$ using Nicolet iS50 FT-IR (Thermo Scientific) coupled with GladiATR (Pike Technologies) with a single reflection monolithic diamond and high pressure device. 
Each spectrum had the average of 64 scans from 525 to $4000 \mathrm{~cm}^{-1}$, with $0.4 \mathrm{~cm}^{-1}$ resolution, and submitted to background subtraction. The measurements were recorded in absorbance. After analysis, all FTIR spectrum were imported to Matlab software and chemometrics analysis were conduced.

\section{Chemometric analysis}

Multivariate data analysis were carried out using MATLAB version 7.1 and PLS_toolbox version 5.8 (Eigenvector Co.). In order to differentiate and to classify pure coffee from adulterated coffee with corn, the PCA was performed, and, to quantify, the PLS was performed.

At first, the DSC curves were normalized by the mass of sample used in each analysis, to eliminate the interference due to the variation of sample amount. Data pre-treatment techniques used were first derivative (Savitzky-Golay, window length: 15 , polynomial order: 2), standard normal variate (SNV) and mean center. First derivative was to highlight the most important data of curve; the SNV is a weighted standardization that calculates the standard deviation of all variables for a given sample, and all data from this sample are normalized to this value, so the standard deviation of the sample is the unit $(\mathrm{s}=1)$ and the normalization is weighted considering the amounts of each sample individually. ${ }^{43,44}$ The optimal numbers of principal components (PCs) were determined by using a leave-oneout cross validation procedure.

For PCA analysis of DSC data, a data matrix was constructed so each row corresponds to a sample. The matrix contains 42 samples ( 9 samples of pure coffee and 33 of binary mixtures) and 20749 variables (corresponding to heat flow $\left(\mathrm{uW} \mathrm{mg} \mathrm{m}^{-1}\right.$ ) from 50 to $600{ }^{\circ} \mathrm{C}$ ). The first 9 samples were of pure coffee at three levels of roaster. A classifying test sample was performed using Mahalanobis distance classification with Ward's method. To estimate the percentage of corn in samples, a PLS model was built using 22 samples for calibration and 11 for validation. The number of latent variables was chosen by cross-validation with leave-one-out method.

The data pre-treatment techniques employed to FTIR spectra were first derivative (Savitzky-Golay, window length: 15 , polynomial order: 2 ), SNV and mean center. For PCA analysis of FTIR data, data matrices were constructed so each row correspond to a sample and each column represents the spectra in a given wavenumber. The matrix contains 108 samples ( 9 of pure coffee and 99 of binary mixtures) and 7209 variables (corresponding to FTIR spectra from 525 to $4000 \mathrm{~cm}^{-1}$ ). The cluster analysis using Mahalanobis distance classification with Ward's method was conducted to classify the samples. The PLS model was built using 66 samples for calibration and 33 for validation with 7209 variables (corresponding to absorbance spectrum of FTIR from 525 to $4000 \mathrm{~cm}^{-1}$ ).

\section{Results and Discussion}

Thermal analysis

Roasted and ground pure coffee, pure corn and mixtures of coffee and corn were analyzed by DSC and their curves can be seen in Figure 1. There are few differences between the DSC curves of three levels of roasting (Figure 1a), therefore it is expected that the level of roasting was not interfered in identifying adulteration of coffee with corn. However, there are visual differences in the DSC curves of coffee and corn (Figure 1b), which are important for the identification of this kind of adulteration.

In Figure $1 b$ is possible to observe an endothermic peak at the region between 65 and $80{ }^{\circ} \mathrm{C}(\mathrm{C} 1)$ present in DSC
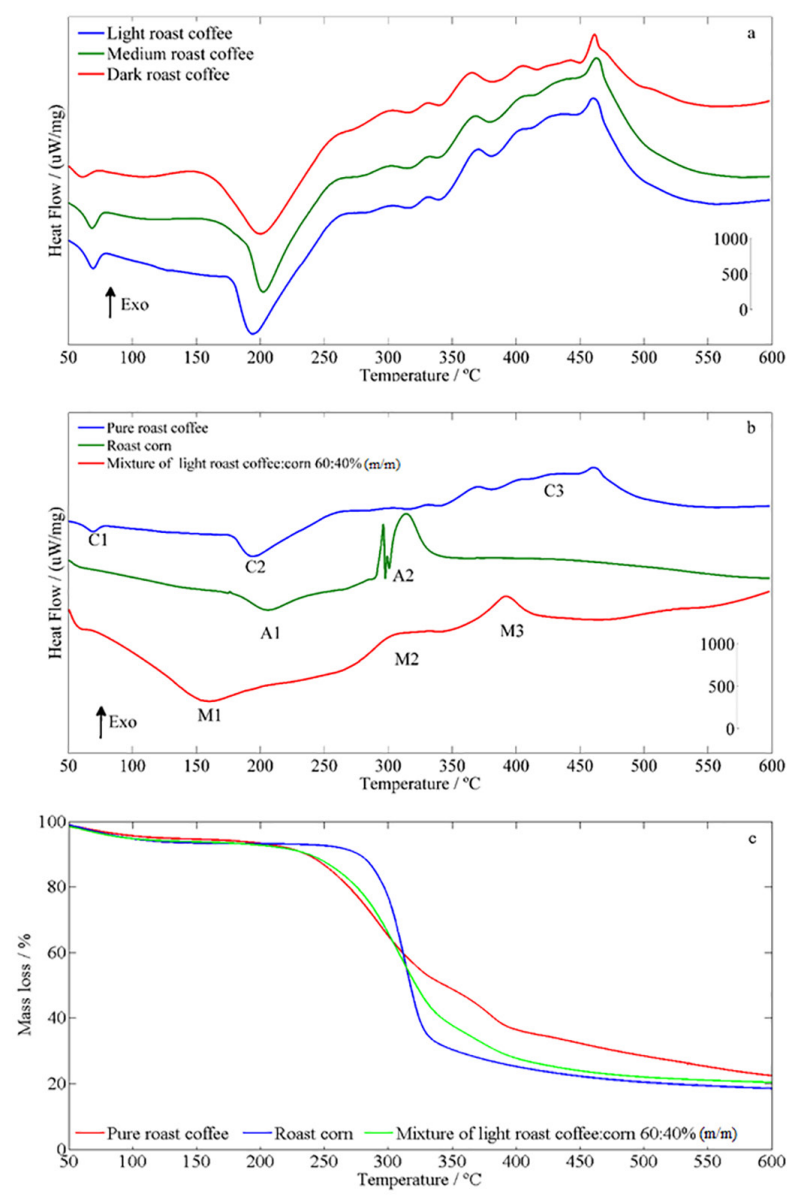

Figure 1. DSC curves of (a) three levels of roast (light, medium and dark roast) of pure coffee samples (averages of $n=3$ ); (b) pure coffee, pure corn and a mixture of coffee and corn $60: 40 \%(\mathrm{~m} / \mathrm{m})$ and (c) TG curve pure coffee, pure corn and a mixture of coffee and corn $60: 40 \%(\mathrm{~m} / \mathrm{m})$. 
curves of pure coffee at three levels of roast. At TG curve (Figure 1c) there is a slightly mass loss of $1-2 \%$ in this region. The temperature and the low percentage of mass loss suggest that it may be related to dehydration process.

The endothermic peak between 175 to $250^{\circ} \mathrm{C}$ present in DSC curves at Figure $1 \mathrm{~b}(\mathrm{C} 2, \mathrm{~A} 1$ and $\mathrm{M} 1)$ is from melting of some constituents like amino acids, lipids and sugars such as sucrose, glucose, fructose, arabinose, galactose, maltose and polysaccharides present in all samples (coffee, corn and mixture). ${ }^{45,46}$

In temperatures above $250{ }^{\circ} \mathrm{C}$ in DSC curves at Figure $1 \mathrm{~b}$ there are exothermic peaks at DSC curves (C3, A2, M2 and M3), and mass loss of approximately $80 \%$, that usually involves breaking bonds and the release of some volatiles compounds. The peak A2, in DSC curve of corn, may be from degradation of corn starch. ${ }^{47}$

Scores and loading PCA matrices were generated using 4 principal components (PCs), describing at total $63.00 \%$ of variance. In the scores plot for the first three PCs (Figure 2a) is possible to observe that the first principal component (PC1) is able to differentiate the pure samples (sample 1 to 9) from adulterated (sample 10 to 42) samples, and that there is a trend of the level of adulteration. There is a trend of as higher the level of adulteration, more distant the samples are from the region of the pure samples, and as lower the level of adulteration, closer the samples are from the region of the pure samples. In Figure 2a is possible to see that the third principal component (PC3) is able to differentiate the level of roaster. Light roast (sample 10 to 20) at top region of the plot, medium roast (sample 21 to 31) at mid region and dark roast (sample 32 to 42 ) at lower region. The clustering analysis was performed and the dendrogram of DSC data obtained using Ward's method and Mahalanobis distance (Figure 2b) shows the separation between the groups of pure coffee samples and the samples of binary mixtures.

The calibration data set of PLS model using DSC curves was composed by 23 samples, and validation data set, 10 samples, in three roast level (low, medium or high). The model was built with 4 latent variables (LVs). The correlation between the values of estimated and reference concentrations values is presented in Figure 3, where a good agreement can be observed. The performance parameters of PLS model are displayed in Table 2.

\section{Infrared spectroscopy analysis}

Roasted and ground coffee and corn were analyzed by ATR-FTIR and their infrared spectra can be seen at Figure 4a. There are no visual differences between the spectra of three levels of roasting, therefore it is expected that the level of roasting will not interfere at identifying adulteration of coffee

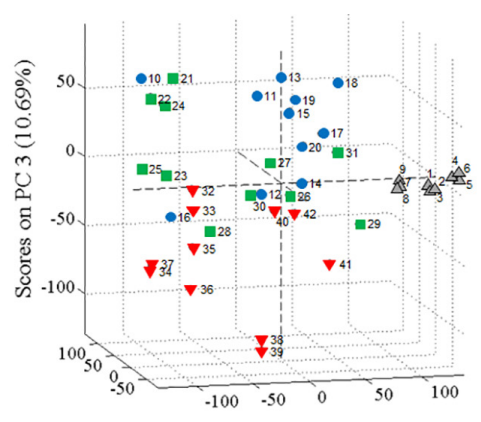

Scores on PC 2 (16.71\%)

Scores on PC $1(35.70 \%)$

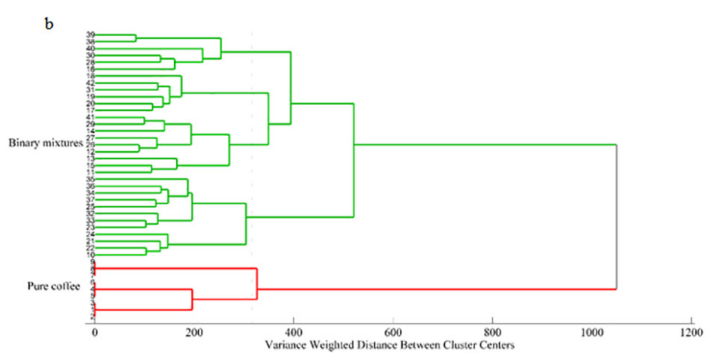

Figure 2. (a) Principal component analysis (PCA) scores plot of PC1 versus $\mathrm{PC} 2$ versus $\mathrm{PC} 3$ of DSC data. Samples 1-3: $(\triangle)$ pure light roast coffee; 4-6: $(\triangle)$ pure medium roast coffee; 7-9: $(\triangle)$ pure dark roast coffee; 10-20: (-) mixtures of light roast coffee and corn; 21-31: ( $\square$ ) mixtures of medium roast coffee and corn; and 32-42: $(\boldsymbol{\nabla})$ mixtures of dark roast coffee and corn; (b) dendrogram from cluster analysis of Mahalanobis distance using Ward's method for 9 samples of pure coffee (red) and 33 samples of adulterated coffee (green).

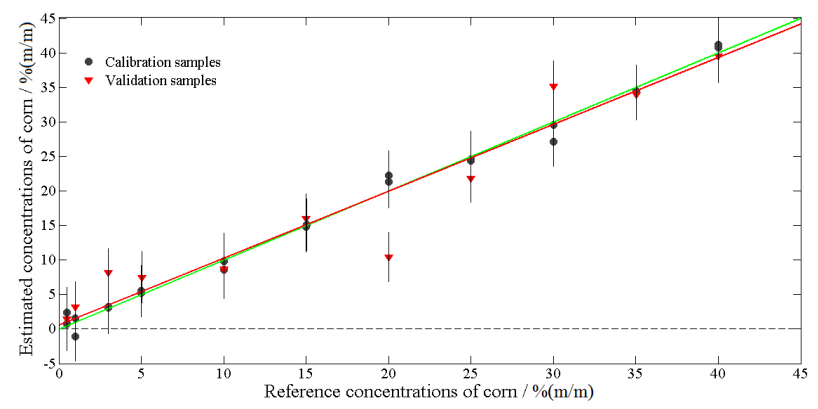

Figure 3. PLS regression and external validation for the corn content in roasted and ground coffee of DSC data. Circle: calibration set; triangle: validation set; and error bars: uncertainty of the estimates values with $95 \%$ of confidence.

Table 2. Performance parameters of PLS model to estimate corn concentration on roasted and ground coffee by DSC and ATR-FTIR

\begin{tabular}{lcc}
\hline Parameter & DSC & ATR-FTIR \\
\hline Latent variables & 4 & 6 \\
RMSEC & 1.15 & 1.25 \\
RMSECV & 3.45 & 2.63 \\
RMSEP & 3.94 & 1.53 \\
$\mathrm{R}^{2}$ calibration & 0.9927 & 0.9915 \\
$\mathrm{R}^{2}$ cross-validation & 0.9351 & 0.9623 \\
$\mathrm{R}^{2}$ prediction & 0.9152 & 0.9876 \\
\hline
\end{tabular}

RMSEC: root mean square error of calibration; RMSECV: root mean square error of cross-validation; RMSEP: root mean square error of prediction $(\% \mathrm{~m} / \mathrm{m})$. 
by corn. However, there are differences between the infrared spectra of roast coffee and roast corn, which are important for the identification and quantification of adulteration by corn.

The visual analysis of ATR-FTIR spectra from samples of mixtures of coffee and corn (Figure 4b) does not allow to detect differences between them, so the PCA were performed in order to separate the samples of pure coffee and the adulterated coffee.
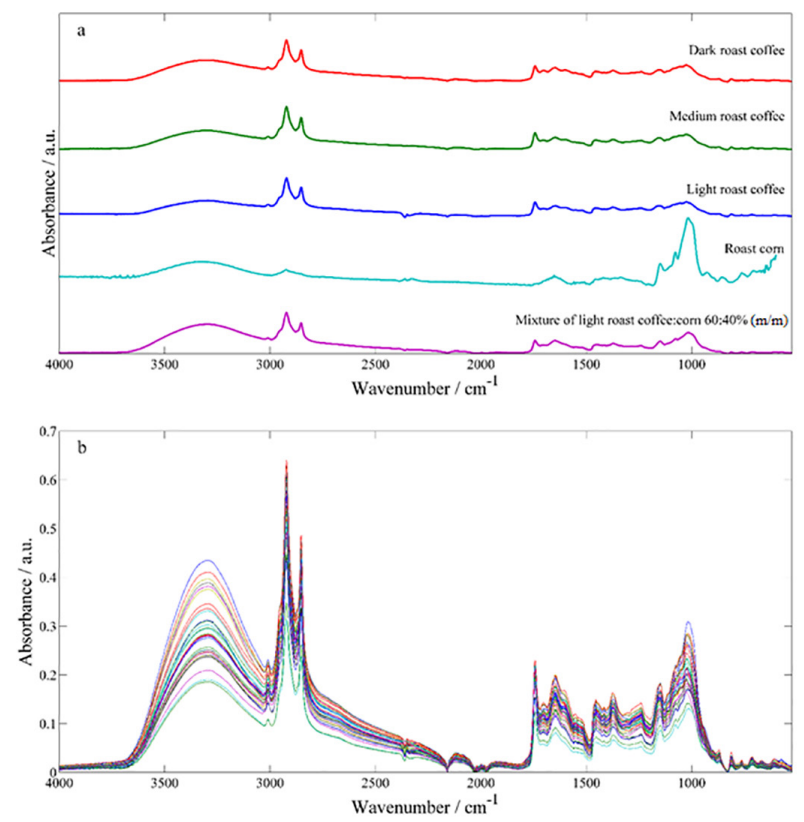

Figure 4. (a) Average $(n=3)$ ATR-FTIR spectra of three levels of roast (light, medium and dark roast) of pure coffee samples, pure roast corn and a mixture of coffee and corn 60:40\% (m/m); (b) ATR-FTIR spectra of mixtures of roasted coffee and corn.

PCA analysis of ATR-FTIR spectra from pure coffee and adulterated samples present 6 PCs describing at total $75.61 \%$ of variance. Figure 5 shows the scores of first three PCs. When the concentration of adulterant is low, the PCA analysis with FTIR is not able to distinguish adulterated coffee from pure one with $95 \%$ of confidence. As observed with the PCA from DSC data, there is a trend of as higher the level of adulteration, more distant the samples are from the region of the pure samples, and as lower the level of adulteration, closer the samples are from the region of the pure samples. The PCA model with FTIR was not able to differentiate from different levels of roast. The clustering analysis was conducted and the dendrogram of DSC data obtained using Ward's method and Mahalanobis distance (Figure 5b) shows the low separation of groups of pure coffee samples and adulterated samples.

To build PLS model the samples of pure roasted and ground coffee were excluded from the calibration and validation due to the presence of a large error in the prediction values when compared with the reference values, so the total
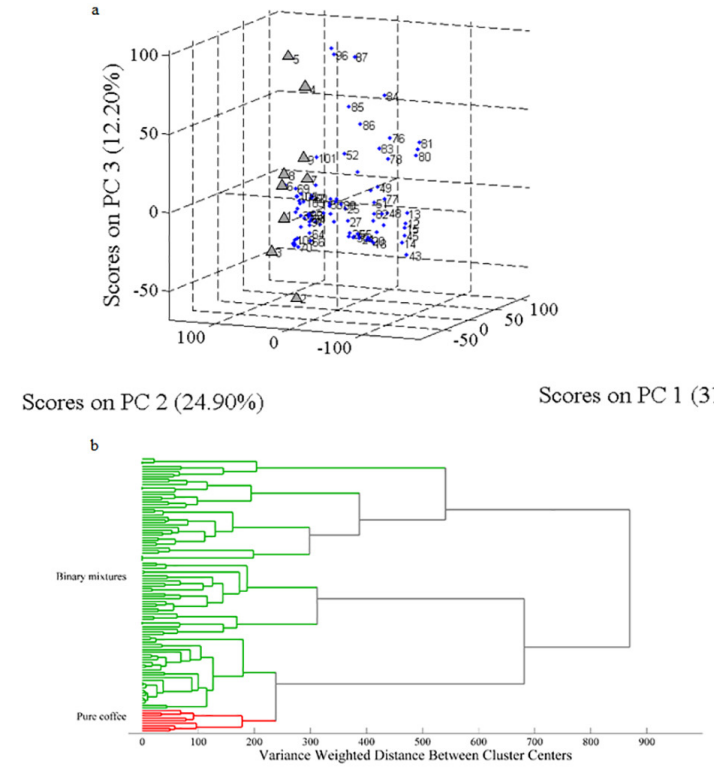

Figure 5. (a) PCA plot of $\mathrm{PC} 1$ versus $\mathrm{PC} 2$ versus $\mathrm{PC} 3$ of ATR-FTIR data. Samples 1-3: $(\triangle)$ pure light roast coffee; 4-6: $(\triangle)$ pure medium roast coffee; 7-9: $(\triangle)$ pure dark roast coffee; 10-42: mixtures of light roast coffee and corn; 43-75: mixtures of medium roast coffee and corn; and 76108: mixtures of dark roast coffee and corn; (b) dendrogram from cluster analysis of Mahalanobis distance using Ward's method for 9 samples of pure coffee (red) and 99 samples of adulterated coffee (green).

number of samples is 99 , being 66 on calibration set and 33 on validation set. The model was built with 6 latent variables (LVs). The correlation between the estimated values and reference concentrations values is presented in Figure 6, where a good agreement can be observed. The performance parameters of PLS model are displayed in Table 2. Comparing the performance parameters values of DSC and FTIR models, both methods are satisfactory to quantify corn adulteration in samples of roasted and ground coffee.

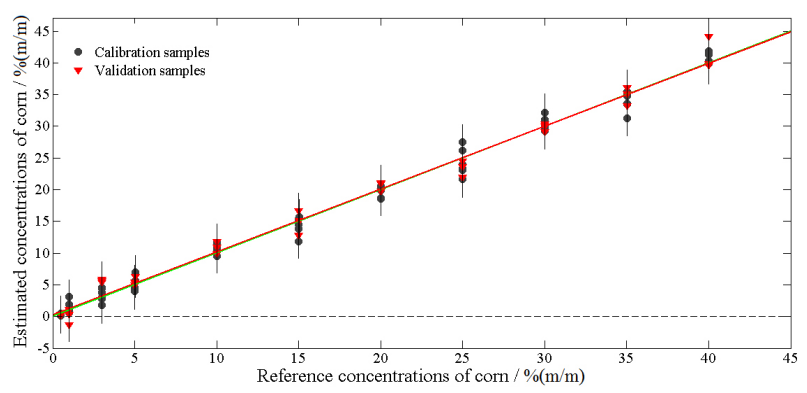

Figure 6. PLS regression and external validation for the corn content in roasted and ground coffee of ATR-FTIR data. Circle: calibration set; triangle: validation set; and error bars: uncertainty of the estimates values with $95 \%$ of confidence.

\section{Conclusions}

DSC and ATR-FTIR coupled with chemometric analysis (PCA and PLS) were performed. Both DSC and 
FTIR coupled with PCA were able to detect adulteration with corn even in concentrations lower than $1 \%$. The methodologies are able to meet the Brazilian current law (Instrução Normatica No. 16, from May 24, 2010 of MAPA), that regulates a maximum level of $1 \%(\mathrm{~m} / \mathrm{m})$ of adulterants. PLS models were built with DSC and FTIR data, and both techniques of analysis have showed good agreement between the values of estimated and reference concentrations, with RMSE lower than $3.4 \%$ for DSC data and $2.1 \%$ for FTIR data.

Thermal analysis, like DSC, is more applied to characterization than to quantification analysis. The results showed that the developed models by DSC analysis are good alternatives to be used in detection of frauds and in quality control of coffee.

It is common to find in literature the use of infrared spectroscopy with PLS to quantification of some adulterants in coffee, but some authors says that DRIFTS provides spectra with higher intensity of absorption than ATR-FTIR, and therefore FTIR could not provide a complete discrimination between adulterated and non-adulterated coffees. ${ }^{7,15}$ In this work it is possible to see the potentiality of ATR-FTIR to detect and quantify the adulteration of coffee due to corn presence, even at low concentrations (less than $1 \%(\mathrm{~m} / \mathrm{m})$ ).

DSC and FTIR are complementary techniques that can offer a reproducible fingerprint for adulteration detection and quantification purposes.

\section{Acknowledgments}

This work was supported by CNPq (Process 483841/2010-2), FAPEMIG and CAPES. The authors would like to thank to Prof Dr Rosemary G. F. A. Pereira (UFLA) for the coffee samples.

\section{References}

1. Garcia, L. M. Z.; Pauli, E. D.; Cristiano, V.; da Camara, C. A. P.; Scarminio, I. S.; Nixdorf, S. L.; J. Chromatogr. Sci. 2009, 47,825 .

2. ABIC, Indicadores da Indústria de Café no Brasil, 2014. Available at http://www.abic.com.br/publique/cgi/cgilua.exe/ sys/start.htm?sid=61\#4178, accessed in November 2016.

3. CECAFÉ, Exportações Brasileiras de Café, 2015. Available at http://www.cecafe.com.br/dados-estatisticos/exportacoesbrasileiras/, accessed in November 2016.

4. United States Department of Agriculture Coffee: World Markets and Trade. Available at https://apps.fas.usda.gov/psdonline/ circulars/coffee.pdf, accessed in November 2016.

5. MAPA; Instrução Normativa No. 16, de 24 de maio de 2010,
Novo Regulamento Técnico para o Café Torrado em Grão e Torrado e Moído; Diário Oficial da União: Brasília, 2010, seção 1, p. 11.

6. Bosque-Sendra, J. M.; Cuadros-Rodríguez, L.; Ruiz-Samblás, C.; de la Mata, A. P.; Anal. Chim. Acta 2012, 724, 1.

7. Reis, N.; Franca, A. S.; Oliveira, L. S.; LWT - Food Sci. Technol. 2013, 50, 715 .

8. Jham, G. N.; Berhow, M. A.; Manthey, L. K.; Palmquist, D. A.; Vaughn, S. F.; J. Braz. Chem. Soc. 2008, 19, 1462.

9. Oliveira, R. C. S.; Oliveira, L. S.; Franca, A. S.; Augusti, R.; J. Food Compos. Anal. 2009, 22, 257.

10. Jham, G. N.; Winkler, J. K.; Berhow, M. A.; Vaughn, S. F.; J. Agric. Food Chem. 2007, 55, 5995.

11. Nogueira, T.; do Lago, C. L.; J. Sep. Sci. 2009, 32, 3507.

12. Amboni, R. D. M. C.; Francisco, A.; Teixeira, E.; Ciênc. Tecnol. Aliment. 1999, 19, 311.

13. Briandet, R.; Kemsley, E. K.; Wilson, R. H.; J. Sci. Food Agric. 1996, 71, 359.

14. Pizarro, C.; Esteban-Díez, I.; González-Sáiz, J. M.; Anal. Chim. Acta 2007, 585, 266.

15. Reis, N.; Franca, A. S.; Oliveira, L. S.; LWT - Food Sci. Technol. 2013, 53, 395.

16. Tavares, K. M.; Pereira, R. G. F. A.; Nunes, C. A.; Pinheiro, A. C. M.; Rodarte, M. P.; Quim. Nova 2012, 35, 1164.

17. Dahimi, O.; Rahim, A. A.; Abdulkarim, S. M.; Hassan, M. S.; Hashari, S. B. T. Z.; Siti Mashitoh, A.; Saadi, S.; Food Chem. 2014, 158, 132.

18. Torrecilla, J. S.; García, J.; García, S.; Rodríguez, F.; J. Food Eng. 2011, 103, 211.

19. Van Wetten, I. A.; Van Herwaarden, A. W.; Splinter, R.; Boerrigter-eenling, R.; Thermochim. Acta 2015, 603, 237.

20. Mohammed, J.; Marikkar, N.; Rana, S.; J. Oleo Sci. 2014, 873, 867.

21. Marikkar, J. M. N.; Ghazali, H. M.; Che Man, Y. B.; Lai, O. M.; Food Res. Int. 2002, 35, 1007.

22. Mansor, T. S. T.; Man, Y. B. C.; Shuhaimi, M.; J. Am. Oil Chem. Soc. 2012, 89, 485.

23. Van Wetten, I. A.; Van Herwaarden, A. W.; Splinter, R.; Van Ruth, S. M.; Procedia Eng. 2014, 87, 280.

24. Cordella, C.; Faucon, J. P.; Cabrol-Bass, D.; Sbirrazzuoli, N.; Ensia; J. Therm. Anal. Calorim. 2003, 71, 279.

25. Cordella, C.; Antinelli, J. F.; Aurieres, C.; Faucon, J. P.; CabrolBass, D.; Sbirrazzuoli, N.; J. Agric. Food Chem. 2002, 50, 203.

26. Tomaszewska-Gras, J.; J. Therm. Anal. Calorim. 2012, 108, 433.

27. Tonetti, C.; Varesano, A.; Vineis, C.; Mazzuchetti, G.; J. Therm. Anal. Calorim. 2015, 119, 1445.

28. Jafari, M.; Kadivar, M.; Keramat, J.; J. Am. Oil Chem. Soc. 2009, 86, 103.

29. Anjos, O.; Campos, M. G.; Ruiz, P. C.; Antunes, P.; Food Chem. 2015, 169, 218. 
30. Botelho, B. G.; Reis, N.; Oliveira, L. S.; Sena, M. M.; Food Chem. 2015, 181, 31.

31. Xu, L.; Shi, W.; Cai, C.-B.; Zhong, W.; Tu, K.; LWT - Food Sci. Technol. 2015, 61, 590 .

32. Zhao, M.; Downey, G.; O’Donnell, C. P.; Meat Sci. 2014, 96, 1003.

33. de la Mata, P.; Dominguez-Vidal, A.; Bosque-Sendra, J. M.; Ruiz-Medina, A.; Cuadros-Rodríguez, L.; Ayora-Cañada, M. J.; Food Control 2012, 23, 449.

34. Gallardo-Velázquez, T.; Osorio-Revilla, G.; de Loa, M. Z.; Rivera-Espinoza, Y.; Food Res. Int. 2009, 42, 313.

35. Jaiswal, P.; Jha, S. N.; Borah, A.; Gautam, A.; Grewal, M. K.; Jindal, G.; Food Chem. 2015, 168, 41.

36. Jawaid, S.; Talpur, F. N.; Sherazi, S. T. H.; Nizamani, S. M.; Khaskheli, A. A.; Food Chem. 2013, 141, 3066.

37. Quinones-Islas, N.; Meza-Marquez, O. G.; Osorio-Revilla, G.; Gallardo-Velazquez, T.; Food Res. Int. 2013, 51, 148.

38. Feng, Y.; Lei, D.; Hu, C.; Spectrochim. Acta, Part A 2014, 125, 363.

39. Rooney, J. S.; McDowell, A.; Strachan, C. J.; Gordon, K. C.; Talanta 2015, 138, 77.
40. Grobério, T. S.; Zacca, J. J.; Botelho, É. D.; Talhavini, M.; Braga, J. W. B.; Forensic Sci. Int. 2015, 257, 297.

41. Reis, N.; Franca, A. S.; Oliveira, L. S.; LWT - Food Sci. Technol. 2013, 50, 715 .

42. Mauer, L. J.; Chernyshova, A. A.; Hiatt, A.; Deering, A.; Davis, R.; J. Agric. Food Chem. 2009, 57, 3974.

43. Ferreira, M. M. C.; Antunes, A. M.; Melgo, M. S.; Volpe, P. L. O.; Quim. Nova 1999, 22, 724.

44. Wise, B. M.; Gallagher, N. B.; Bro, R.; Shaver, J. M.; Windig, W.; Koch, R. S. Chemometrics Tutorial for PLS_Toolbox and Solo; Eigenvector Research: Wenatchee, 2006, p. 414.

45. Li, X.; Strezov, V.; Kan, T.; J. Anal. Appl. Pyrolysis 2014, 110, 79.

46. Liu, X.; Ma, H.; Yu, L.; Chen, L.; Tong, Z.; Chen, P.; J. Therm. Anal. Calorim. 2014, 115, 659.

47. Pineda-Goímez, P.; Rosales-Rivera, A.; Rodríguez-García, M. E.; Starch/Staerke 2012, 64, 776.

Submitted: September 14, 2016 Published online: November 11, 2016 